\section{Response: "Autonomy and the Moral Status of Animals"}

\section{James Lindemann Nelson Michigan State University}

Autonomy has been one of the most crucial concepts in moral philosophy since the Enlightenment; it has been equally important in the forms of moral practice that have developed during that time, in particular, in the drive for more democratic social structures. And its importance hasn't flagged, in either theory or practice, in our culture's most recent reflections about the nature and demands of ethics. But at the same time it is a highly contentious concept, both in terms of how it should be understood, and of its implications for how we ought to live our lives. In these remarks I will establish a context designed to underscore both the continuing significance and the continuing controversy surrounding autonomy.

\section{The Idea of Autonomy: A Rough Characterization}

A "smooth" characterization of autonomy would require a great deal of space to work out and defend, and would still be subject to disagreement. But the conceptual neighborhood autonomy occupies can be indicated fairly succinctly: Autonomy involves the notion of being free to choose one's own values and actions. This is a familiar idea, and one whose moral importance is fairly apparent, at least in our time and place: We feel the loss of something very important if we are deprived of our liberty. If our choices or actions are manipulated by the force or the deception of others, we tend to feel as though our importance as persons is too cheaply regarded.

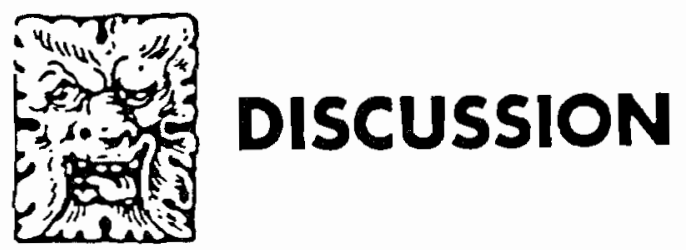

If the idea of autonomy is readily accessible, some of its complexities lie pretty close to the surface as well: Even without blatant force or fraud, how free are we really to choose and act on those choices? What is the bearing of our environment and our genetic heritage on what we wish and what we do? Can such influences be resisted? To what extent is the viability of autonomy as a moral notion dependent on human life's not being determined by causal regularities?

Most moral examinations of autonomy proceed as though there were satisfactory answers to these questions in place, and to a large extent, this is true of this symposium as well. It is more directly to the present point to sketch out the lines of another dispute: How and why is autonomy morally significant at all?

\section{The Significance of Autonomy: Views from Moral Theory}

There are two major positions on this issue. Some thinkers regard autonomy as morally significant intrinsically. The most uncompromising proponent of this view historically is probably Immanuel Kant, who regarded the possession of autonomy as essential for having any moral standing at all; once possessed it has an overriding impact on the ways that one should be treated. As Kant would have it, an autonomous being is a person, and persons ought never be treated solely as means to ends but always as "ends in themselves." Kant saw any being or action that was not autonomous, but simply a part of the closed, causally determined system of Nature, as without moral worth. Nonhuman animals, therefore, are without any direct moral standing for Kant, although we do need to take care about how our treatment of animals might influence our behavior toward other persons. Contemporary philosophers influenced by Kant do not necessarily follow him in denying any moral standing to nonautonomous beings or actions, but they tend to agree that autonomy is crucial to the possession of moral rights.

The tradition in moral theory more heavily indebted to John Stuart Mill-utilitarianism-regards autonomy as important not in itself, but because of its important contributions to what is important in itself. If, for instance, one takes happiness to be the only things that is an intrinsic good, then autonomy is morally important just to the extent that honoring it leads to greater happiness. Mill and others have argued that respecting the autonomy of human beings is strongly conducive 
to happiness, for an adult can be generally presumed to know her own interests better than others will, and because, as noted earlier, being coerced by others, even if their motivation is benevolent, typically makes us very unhappy.

It is worth noting that because this tradition in moral theory sees traits other than autonomy as ethically important, it is often more hospitable to nonhuman animals (on the widely shared assumption that the relevant senses of autonomy do not apply to nonhumans).

Both broad concepts of autonomy have been influential in recent movements of moral reform, with interesting results for both our moral practice, and our moral understanding.

The Significance of Autonomy:

\section{Views from Contemporary Social Movements}

The idea of autonomy has played a major role in many of the social practices that have recently undergone rapid and significant change. Three social movementspatients' rights, the women's movement, and the movement to liberate animals-are particularly instructive.

In health care, both legal and moral theory, followed (to some extent) by clinical practice, have moved decisively away from the paternalistic idea that "doctor knows best" about the kind of heal th care decisions that ought to be made for a patient, and toward the notion that the free and informed consent of patients is a basic requisite for acceptable medical interactions. A parallel shift seems to lie at the heart of the women's movement; it has rejected the idea that women's lives and choices should be determined by a patriarchal system that subordinates their interests to those of men. Similarly, many animal liberationists have insisted that we abandon the notion that animals are simply there for our use, even if we avoid cruelty in our dealings with them. Animals have lives of their own, on this view, and aren't just means to our ends.

All this is clearly a movement in the direction of greater respect for the autonomy of patients, of women, and of nonhumans. But while appeal to the moral importance of respecting autonomy has figured importantly in these and other movements for moral change, all three have yielded problems and insights that have made the concept of autonomy seem even more complex and problematic.
A good deal of contemporary health care, for example, is directed toward the no-longer autonomous, the not-yet autonomous, those who will never be autonomous, and those of diminished autonomy. Many medical ethicists maintain that an autonomous person's "moral advantage, is restricted to her being (in general) an authoritative source of information concerning her values, and hence, an authoritative decision-maker. Those who lack autonomy cannot occupy that role, but there is an equal moral obligation to tailor treatment decisions to the patient's values, not those of her caregivers; the trick, of course, is to determine what those values are.

Many feminist theorists have in recent years expressed real concern about the logical, causal, and metaphorical irnplications of autonomy, or at least of certain understandings of the notion. They are suspicious that an ethic centered on autonomy presents a too highly individualized picture of moral relationships - at least, too highly individualized to accurately represent the moral situations characteristic of women-and that a focus on autonomy tends to discourage taking proper moral account of the value of concern and connectedness, of compassion and care.

And finally, the animal liberation movement has contributed to reconsiderations of both autonomy's range and its importance. It has explored the implications of the fact that nonhumans have strong preferences and can make choices reflecting them. Also, along with feminist theorists and medical ethicists, philosophers interested in animals have suggested that autonomy may need to be taken down a peg or two as a determinant of moral standing.

It is this second theme that Professor Comstock explores in his paper. Fixing on a particular analysis of autonomythat provided by R. G. Frey-he attempts to demonstrate that a human life may fail to be autonomous in that sense, yet be worthy of moral respect and protection. He suggests further that some of the moral qualities we respect in his exemplar, a woman named Carrie, may be due to her very lack of autonomy, as Frey conceives of it. The implication of Professor Comstock's paper is clear: If a human being needn't possess autonomy for her life to be considered with moral respect, there is no justification for regarding autonomy as the secular analog to the traditional notion of an immortal soul-the "bright line" separating humans from nonhumans that allows us to manipulate and end animal lives with impunity.

Professor Francis' commentary raises questions about whether Comstock's understanding of autonomy 
is overly individualistic, linking the notion too closely to "a rejection of background and tradition." She also suggests that Carrie's life might well be enhanced were both she and others to have a greater respect for her autonomy, and ends by claiming that line drawing is not the appropriate metaphor for sorting out the moral complexities of intraspecific ethics.

Professor Sapontzis, like Comstock, reads Frey as asserting that autonomy is a crucially important determinant of a being's moral standing, but can find no justification for assigning it such an overweening status. As Sapontzis sees it, valorizing autonomy is a result of either logical errors, or of arbitrarily insisting that the preferences of a subclass of human beings ought to be a universally valid standard of moral worth. Furthermore, even were Frey able to show that possessing autonomy did confer on human beings "moral superiority," it would not follow that humans had the right to exploit and kill nonhumans.
Professor Frey* has many reservations about Comstock's analysis - he is not convinced, for instance, that Carrie's life is bereft of autonomy in the same way that the lives of nonhumans are - but his main objection is that his position has been misconstrued. As a utilitarian, he does not assign to autonomy any kind of "trump card" status. Possessing autonomy does not guarantee the inviolability of one's life or other interests against sufficiently important competing interests. Nor does lacking it render a being without moral value.

All these essays inspire reflection on how to refine our understanding of autonomy, and on why it is morally important. Such activity is a genuine contribution to moral discourse about the place of nonhumans in a secular, pluralistic society.

* Professor Frey's commentary, presented at the March, 1990 Society for the Study of Ethics and Animals meeting, was not available for publication.

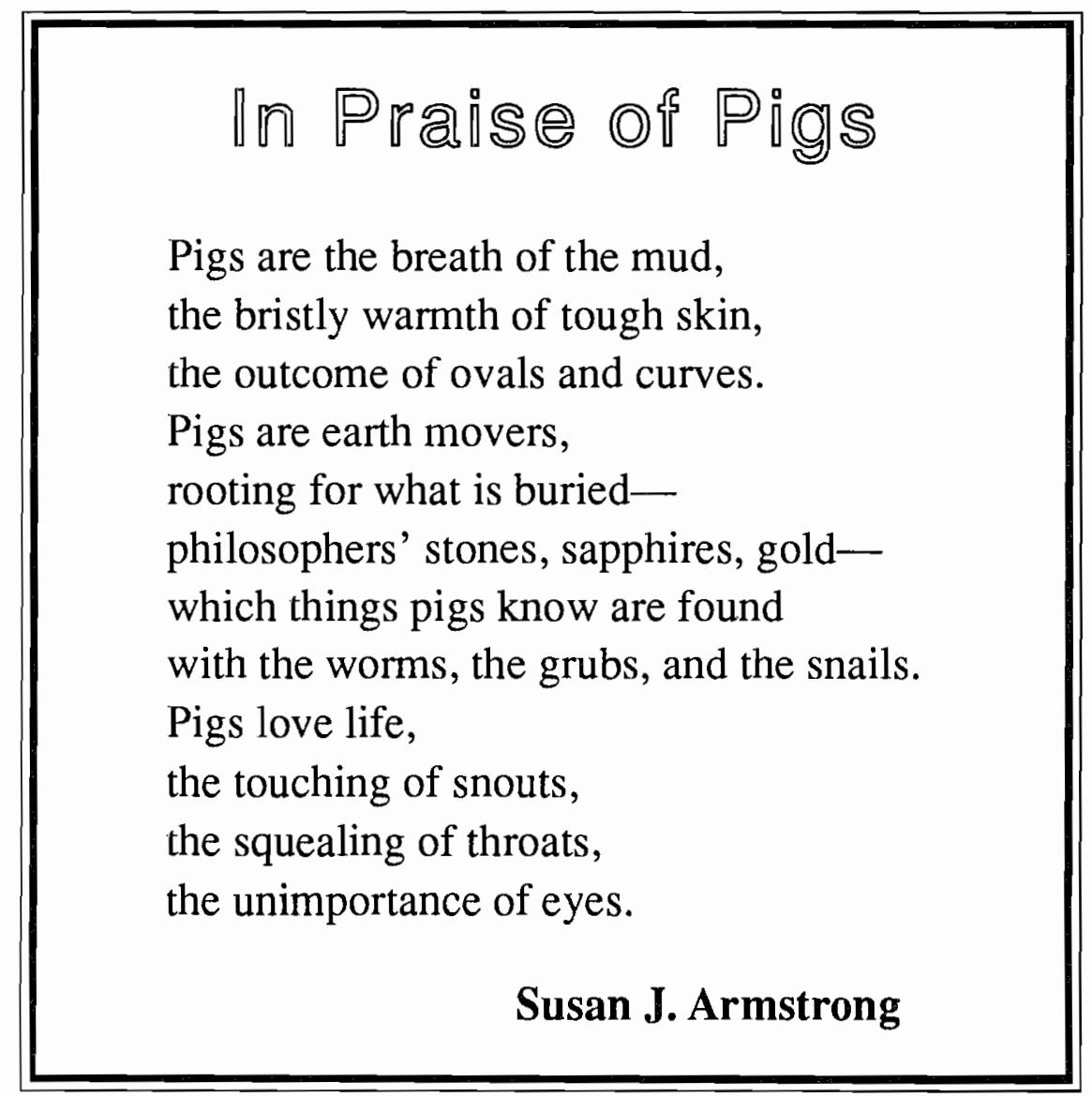

